\title{
A goal management intervention for polyarthritis patients: rationale and design of a randomized controlled trial
}

\author{
Roos Y Arends ${ }^{1,2^{*}}$, Christina Bode ${ }^{1,2}$, Erik Taal ${ }^{1,2}$ and Mart AFJ Van de Laar ${ }^{1,2,3}$
}

\begin{abstract}
Background: A health promotion intervention was developed for inflammatory arthritis patients, based on goal management. Elevated levels of depression and anxiety symptoms, which indicate maladjustment, are found in such patients. Other indicators of adaptation to chronic disease are positive affect, purpose in life and social participation. The new intervention focuses on to improving adaptation by increasing psychological and social well-being and decreasing symptoms of affective disorders. Content includes how patients can cope with activities and life goals that are threatened or have become impossible to attain due to arthritis. The four goal management strategies used are: goal maintenance, goal adjustment, goal disengagement and reengagement. Ability to use various goal management strategies, coping versatility and self-efficacy are hypothesized to mediate the intervention's effect on primary and secondary outcomes. The primary outcome is depressive symptoms. Secondary outcomes are anxiety symptoms, positive affect, purpose in life, social participation, pain, fatigue and physical functioning. A cost-effectiveness analysis and stakeholders' analysis are planned.

Methods/design: The protocol-based psycho-educational program consists of six group-based meetings and homework assignments, led by a trained nurse. Participants are introduced to goal management strategies and learn to use these strategies to cope with threatened personal goals. Four general hospitals participate in a randomized controlled trial with one intervention group and a waiting list control condition.

Discussion: The purpose of this study is to evaluate the effectiveness of a goal management intervention. The study has a holistic focus as both the absence of psychological distress and presence of well-being are assessed. In the intervention, applicable goal management competencies are learned that assist people in their choice of behaviors to sustain and enhance their quality of life.
\end{abstract}

Trial registration: Nederlands Trial Register $=$ NTR3606, registration date 11-09-2012.

Keywords: Adjustment, Self-management, Psychological well-being, Depression, Chronic disease, Adaptation, Threatened goals, Rheumatoid arthritis, Coping, Positive psychology

\section{Background}

The World Health Organization's definition of health was first stated in 1948 as: 'a state of complete physical, mental and social well-being and not merely the absence of disease or infirmity' [1]. Current health systems are still, to a large extent, organized around treatment and cure of specific diseases, reflecting only the second part

\footnotetext{
* Correspondence: R.Y.Arends@utwente.nl

${ }^{1}$ Arthritis Centre Twente, Enschede, The Netherlands

${ }^{2}$ Department of Psychology, Health \& Technology, University of Twente,

P.O. Box 217, 7500 AE, Enschede, The Netherlands

Full list of author information is available at the end of the article
}

of the WHO's definition of health. This results in a focus on disease instead of on health and well-being. We believe that, particularly in the case of chronic diseases, the focus needs to shift to stimulate adaptation to disease and to achieve well-being. We introduce an intervention aimed at people with a chronic condition, based on the capacities and needs of the individual person. The new intervention is based on goal management and is designed to improve peoples' adaptation to their condition of polyarthritis. Therefore, the intervention focuses on increasing psychological and social well-being 
and decreasing symptoms of affective disorders. In this article, the theoretical background and the content of the intervention are described. Furthermore, we describe the design of a randomized controlled trial on the effectiveness of the intervention for increasing adaptation to polyarthritis.

\section{Adaptation to chronic disease}

Suffering a chronic disease increases the risk for the development of secondary conditions and disabilities that often lead to further declines in health status, independence, functional status, life satisfaction, and overall quality of life [2]. Aside from the physical effects and requirements concerning lifestyle changes, a chronic disease often has major psychological and social consequences for patients. Instead of being seen as a 'distinct biological entity existing alone and apart from the person' [3], a chronic disease often becomes part of the identity of a person. In essence, all chronic diseases present a similar set of challenges to the patients and their families including dealing with symptoms, disability, emotional impact, complex medical regimens, difficult lifestyle adjustments, and securing helpful medical care [4]. According to the International Classification of Functioning, Disability and Health (ICF), individuals with chronic and disabling conditions are fully capable of being healthy and experiencing a satisfying subjective quality of life [2,5]. Notwithstanding this perspective, psychological distress is common in persons with polyarthritis [6], indicating that adaptation to the disease is not necessarily natural. For example, patients with rheumatoid arthritis (RA), one of the most common forms of polyarthritis, experience elevated levels of depressive mood and anxiety in comparison with healthy controls [7,8]. Research indicates 20 to $40 \%$ of RA patients suffer from heightened depression and anxiety levels [7,9-12], and depressive and anxiety symptoms are seen as key indicators of unsuccessful adaptation to polyarthritis. However, the absence of psychological distress is not the only essential outcome of adaptation; well-being is similarly essential $[5,12,13]$. For example, emotional well-being is found to predict long-term prognosis of physical illness; higher levels of emotional well-being tend to benefit recovery and survival rates [14].

The inclusion of the following three constructs reflects a comprehensive view on adaptation: positive affect, purpose in life and social participation. Studies have shown that, when levels of pain are elevated in patients with arthritis, positive affect was able to prevent an increase in negative affect $[15,16]$. Furthermore, the level of purpose in life of people with RA was found to be lower in comparison with healthy persons [17] and other studies showed that polyarthritis had a negative influence on the social participation and the work ability of the people affected [18-20]. We hope to capture the full effect of the goal management intervention by taking into account the influence the intervention has on both negative and positive indicators of adaptation to polyarthritis.

\section{Self-management versus health promotion}

The management of most chronic diseases is an extensive responsibility that takes place mostly outside the healthcare system, as people have to manage a chronic disease everyday in combination with possibly conflicting roles and tasks [21]. In fact, the patient, family and community have become active participants in managing chronic disease [22]. Therefore, active self-management and interventions supporting patients in the acquisition of skills and techniques to that help patients learn to live with their disease are seen as essential [23]. A wide variety of selfmanagement interventions has been developed for several chronic conditions. Self-management is 'the individuals' ability to manage the symptoms, treatment, physical and psychosocial consequences and lifestyle changes inherent in living with a chronic condition' [24]. Reasonable evidence exists that self-management interventions are beneficial for a wide population of people with chronic diseases, for example, persons with diabetes, hypertension, heart disease and macular degeneration $[25,26]$.

Despite receiving substantial attention in the literature, fewer benefits attained by persons with inflammatory arthritis have been reported [25]. Usually the effects of self-management interventions found for people with inflammatory arthritis are negligible to small [23,27]. Also, improvements are rarely sustained over a longer time (e.g., 9 to 14 months follow-up) [27-29]. The aforementioned term 'self-management' is used in literature to describe both health-oriented and disease management interventions [26], and this may cause confusion regarding the content and focus of interventions. The most frequently offered and studied self-management program for people with arthritis is the Arthritis Self-Management Course [30,31], in which common problems with day-to-day care of arthritis patients are central.

Most self-management interventions deal with the medical and behavioral management of a chronic disease, but changing roles and emotional distress due to the disease are not systematically incorporated into intervention programs [26]. Health protection or disease management interventions are motivated by the desire to control and manage illness and its consequences [32] and accommodate the unilateral focus on disease and disability. Health promotion, in contrast, is not disease or illness specific, but has illness or disability as context [33]. Moreover, health promotion interventions are intended to promote health and well-being, reflecting the aforementioned perspective of the ICF [5] that individuals with chronic and disabling conditions are fully capable of being healthy and experiencing a satisfying quality of life. Although both 
health promotion interventions and disease management interventions may focus on similar behaviors (e.g., exercise and medication adherence for persons with arthritis), there is a critical difference in the key outcomes assessed. Studies on disease management interventions usually do not include positive psychological and social well-being measures as outcomes. As opposed to common outcome measures of disease-specific self-management interventions (e.g., pain and disability), the outcomes of health promotion interventions should reflect the broad perspective of the $\mathrm{WHO}$ on adaptation to a chronic disease [5]: the experience of quality of life and being healthy in psychological and social terms.

This article introduces a health promotion intervention based on goal management theory developed for people with polyarthritis. Instead of a focus on the management of the disease (as, for example, delivered by the Arthritis Self-management Course), attention is given to how the patient can cope with activities and life goals that have become impossible to attain or are threatened due to arthritis [12]. We will explain the theory upon which the intervention is based in the next sections.

\section{A health promotion intervention based on goal management: a different approach}

The key features of the goal management intervention arise from the characteristics of a health promotion intervention (Table 1). Although these key features are interrelated, we briefly discuss them individually. Firstly, the aim of the intervention is to improve psychological health as well as social and physical functioning. These concepts are intertwined and the intervention is, therefore, aimed to all three concepts. Secondly, the aim of the intervention

Table 1 Goal management intervention versus diseasespecific self-management interventions

\begin{tabular}{|c|c|c|}
\hline Difference in: & $\begin{array}{l}\text { Disease-specific self- } \\
\text { management intervention }\end{array}$ & $\begin{array}{l}\text { Goal management } \\
\text { intervention }\end{array}$ \\
\hline $\begin{array}{l}\text { Aim of } \\
\text { intervention }\end{array}$ & $\begin{array}{l}\text { Control and management } \\
\text { of disease }\end{array}$ & $\begin{array}{l}\text { Maximizing psychological } \\
\text { health, social and physical } \\
\text { functioning }\end{array}$ \\
\hline $\begin{array}{l}\text { Focus / } \\
\text { approach }\end{array}$ & Reductionist & Holistic \\
\hline Perspective & $\begin{array}{l}\text { Patient-centered (disease- } \\
\text { specific orientation) | } \\
\text { Outsiders' perspective } \\
\text { (disease) }\end{array}$ & $\begin{array}{l}\text { Person-focused (body } \\
\text { systems are interrelated) | } \\
\text { Insider's perspective } \\
\text { (illness) }\end{array}$ \\
\hline Content & Disease-specific & $\begin{array}{l}\text { Multiple-related diseases | } \\
\text { Not disease-specific }\end{array}$ \\
\hline $\begin{array}{l}\text { Subject- } \\
\text { matter }\end{array}$ & $\begin{array}{l}\text { Predetermination of course } \\
\text { content }\end{array}$ & $\begin{array}{l}\text { Room for personal } \\
\text { problems and difficulties }\end{array}$ \\
\hline Acquisition of & $\begin{array}{l}\text { Specific competencies for } \\
\text { predetermined assumed } \\
\text { problems }\end{array}$ & $\begin{array}{l}\text { General multi-deployable } \\
\text { competencies }\end{array}$ \\
\hline
\end{tabular}

Based on: Starfield, 2011 [34]; Lorig \& Holman, 2003 [26]; and Stuifbergen et al., 2010 [2]. follows the idea that a holistic approach comprises all aspects of the patient's life. Thirdly, the perspective is person-focused as opposed to an orientation towards a patient-centered disease held by most self-management interventions. In a person-focused view, body systems are seen as interrelated [34] and the illness as experienced by the patient becomes central. This perspective is opposed to a disease or outsiders' viewpoint. In a disease perspective, the focus is placed on a set of symptoms that together form a disease, which implies a particular treatment. Multimorbidity or psychosocial problems play no explicit role in this perspective. The fourth point is that the content of the goal management intervention centers around capabilities and personal potential, and, therefore, can be applied in different disease populations.

Fifth, patients give substance to their own personal trajectory, in contrast to self-management interventions with a predetermined course content [26]. The sixth distinctive feature is that patients learn general applicable goal management competencies that are not disease or problem specific, but can be used in daily life for various difficult situations. Acquiring these goal management competencies aptly complements the health promotion tradition as these competencies assist people in the choice of behaviors that sustain and enhance quality of life within the context of living with a chronic disease [2]. Also, as the focus is on using the existing possibilities and social network of a person and one's own abilities to solve problems, the goal management intervention will promote resilience. Although the intervention described in this article is, in the first instance, developed for people with polyarthritis, due to all the intervention's key features, it can easily be adapted for other chronic diseases or disabilities.

\section{Goal management}

The intervention was developed based on theories of goal management. Having and striving for personal goals can give structure and meaning to life and keep a person engaged in meaningful activities [35,36]. Striving for personal goals may, however, also produce negative psychological effects when people are unable to progress to a desired goal $[37,38]$. Goal management strategies (possible ways to react to difficulties along the path towards a goal) are intended to minimize discrepancies between the actual situation and the goals a person has [12]. The Integrated Model of Goal Management [12] combines strategies from two different theories, namely the dual process model of assimilative and accommodative coping [39-41] and the Goal adjustment model [42]. The resulting four goal management strategies can be applied in different situations. Firstly, the strategy goal maintenance which implies active attempts to alter unsatisfactory life circumstances and situational constraints in accordance with personal preferences [40]. Secondly, the strategy 
goal adjustment is an approach to adjust personal goals to the personal limit of what remains possible when facing difficulties on the path to a goal [40]. Goal adjustment is the revision of self-evaluative standards and personal goals in accordance with perceived deficits and losses. Thirdly, the strategy goal disengagement is theorized to be one of the poles of the continuum of goal adjustment, as disengagement is an ultimate form of adjusting goals, namely, letting go of goals. Goal disengagement is applied when goals are experienced as no longer attainable [35,42]. This strategy implies the withdrawing of effort and commitment from an unattainable goal, having the benefit of releasing limited resources that can be deployed for engaging in new goals and alternative goals. Finally, the strategy goal reengagement implies identifying, committing to and starting to pursue new goals [42]. New goals can fill the space created by the release of unattainable goals.

\section{Polyarthritis}

For patients with polyarthritis, maintaining one's life goals from before disease onset is often impossible [43]. The term polyarthritis is used to indicate a variety of disorders, including rheumatoid arthritis (RA), psoriatic arthritis and ankylosing spondylitis. People with polyarthritis generally experience inflammation and swelling in joints, and despite improved medical treatment in the last decades, persisting pain, fatigue, disability, deformity, distress and reduced quality of life are daily stressors that patients have to cope with $[44,45]$. As a consequence, patients often face difficulties with attaining or maintaining goals in several domains of life, including work, social relationships, leisure activities and domestic tasks [46,47]. The loss of valued life activities, in particular declines in the ability to perform recreational activities and engage in social interactions, is found to be a predictor of the development of depressive symptoms [48].

\section{Goal management and adaptation to polyarthritis}

Both striving for goals (the strategies of goal maintenance and goal reengagement), as well as accepting a given situation and the scaling down of goals (goal disengagement and goal adjustment) are of great value for adaptation. A previous study indicates that the tendency to use these strategies is associated with adaptation to arthritis [12]. Especially for people with inflammatory arthritis, who must deal with the disease's unpredictable and fluctuating course, being able to use different approaches across situations can be beneficial [49]. An intervention based on the flexible use of goal management strategies could be promising as it can teach persons to respond to the demands of any situation in an appropriate way. The ability to use a variety of strategies across different situations is denoted by coping flexibility [50]. Despite its possible benefits for adjustment, coping flexibility is rarely studied in the context of chronic disease [51]. One study showed that an increase in coping flexibility was associated with a decreased depressed mood in patients with arthritis [52].

\section{Aims of the current study}

For methodological reasons we have chosen one primary outcome and several secondary outcomes. Because of its comparability with other research, depressive symptoms are the main focus in this study. Firstly, depression in patients with arthritis is a well-researched and documented phenomenon [48,53-55]. The second reason is that most research on goal management in other patient groups also focused on depression as (one of the) main outcome measure(s) [41,56-58]. Our main hypothesis is that the goal management intervention leads to a significant reduction of depressive symptoms in polyarthritis patients compared to the control condition. In addition, we hypothesize a significant reduction in anxiety symptoms, and a significant improvement in positive affect, purpose in life and satisfaction with participation in patients receiving the intervention as compared to the control condition. We further explore the effect of the intervention on the disease-related outcomes of pain, fatigue and physical functioning.

Moreover, we hypothesize that the ability to use all four goal management strategies and to choose between them depending on the situation mediates the intervention's effect on depression. Goal management competencies are also hypothesized to mediate the intervention's effect on the secondary outcomes of anxiety, positive affect, purpose in life and satisfaction with participation. Traditionally, self-efficacy for coping with disease symptoms is found to be correlated with the effect of disease-specific selfmanagement interventions for arthritis patients [30]. Although the goal management intervention is not explicitly designed to increase self-efficacy, we plan to study selfefficacy as an additional putative mediator on the primary and secondary outcomes. Finally, the cost-effectiveness of the intervention is analyzed in terms of medical and nonmedical costs. It is conceivable that, in the long run, nonmedical costs might decrease because of more realistic planning behavior and decreased absenteeism from work. Additionally, a stakeholders' analysis of the goal management intervention is executed in order to support and promote future implementation.

\section{Methods and design}

\section{Participants}

The study has been approved by the medical ethics committee Twente, number NL40257.044.12. Participants are recruited via arthritis clinics in four general hospitals in The Netherlands, located in the East and Southeast areas of the country. Moreover, people from existing databases 
of research participants are invited to participate. Also local newspapers and contacts with patient organizations are used to reach potential participants. The process for obtaining participant informed consent is in accordance with all applicable regulatory requirements.

The research population consists of people with polyarthritis (as defined by the DBC classification system) with a psychological risk profile. The specific inclusion criteria are: 1) age of 18 years or over, 2) diagnosis of polyarthritis, and 3) score of four or higher on the depression subscale of the Hospital Anxiety and Depression Scale (HADS). People with severe distress are excluded and the treating rheumatologist is informed. Severe distress is measured as a total score on the HADS (the total of both the depression and anxiety subscales) of 22 or higher. The cut-off score is based on literature $[59,60]$. In addition, insufficient Dutch language skills and actual enrolment in psychotherapeutic treatment at the moment of study are exclusion criteria.

\section{Randomization}

The participants are assigned in a 1:1 ratio to either the experimental group or the control group. Patient allocation is be done by means of blocked stratified randomisation per site in random block sizes of 2 and 4 to make sure that both conditions are equally distributed in each participating hospital. The study is open label, as it is impossible, due to the nature of the program, to blind the staff and participants involved to the condition which the patient is allocated.

\section{Experimental condition}

The program consists of six group-based meetings with 8 to 10 participants and individual homework assignments. "Doelbewust!" is a protocol-based psychosocial educational program. Doelbewust is the Dutch word for "purposefully" and we have translated this program name into English as "Right On Target". The program is led by a trained nurse. Participants are introduced to different goal management strategies and learn to use these strategies to cope in a flexible way with threatened personal goals. The goal management strategies that are covered in the program are: goal maintenance, goal adjustment, goal disengagement, and goal reengagement [39-42].

Table 2 lists the topics, goals, and applied techniques for each meeting of the program. The general structure of each meeting is as follows: a short review of the contents of the previous meeting; introducing the topics of the current meeting; elaborating the topics by group discussions and by practicing in individual, dual and group exercises; and explaining homework assignments for the next meeting. A pilot was executed to test the feasibility of the program protocol.

\section{Topics}

In the first meeting participants are encouraged to think about the influence arthritis has on their lives. Four narratives of fictive patients are introduced that are used throughout the whole program to discuss adaptation and the use of goal management strategies. Themes presented in the narratives are threatened personal goals, the goal management strategies, the role of the social environment, and accompanying emotions. Central in the first meeting is recognition, accomplished through comparison of the participant's own situation with the aforementioned narratives and through the exchange of experiences with other participants. Topics in the second meeting are identifying threatened personal goals and becoming acquainted with the various goal management strategies. Participants are encouraged to explore attitudes, behaviors and emotions related to the goal management strategies, using figures that depict the various strategies (Figure 1).

By formulating lower and higher order goals and discussing the goal management strategies, participants gain insights into their own behavior and preferences for strategies regarding vital threatened goals. In addition, by using the goal hierarchy pyramid (see Figure 2) to differentiate between higher order and lower order goals, participants will be helped to choose suitable goal management strategies for threatened goals at a later stage.

During the next meetings, participants choose a threatened activity and a suitable goal management strategy, and formulate and execute a personal action plan for the activity (meetings 3, 4 and 5). Every step in this process is evaluated individually by homework exercises and discussed in a group setting. In the fourth meeting, resistance to change and support from the social environment are also addressed. Central in the fifth and sixth meetings is the execution of alternative goal management strategies. In the sixth meeting, the consolidation of learned skills and competencies and the prevention of relapse in unbeneficial behavior are also addressed. Personal warning signs are used to anticipate a relapse into undesired behavior and also the use of support from the social environment is stimulated to prevent relapse.

\section{Behavior change techniques}

Many health psychologists have argued for a more precise description of intervention content, including specifying techniques used to accomplish behavior change [61]. The explicit communication of intervention content is necessary to study effective ingredients and to further improve the effectiveness of interventions in the future. In the context of these developments, the techniques used in the program are listed for each meeting in Table 2. A couple of techniques that originated from cognitive behavior therapy are 
2. Important personal goals

Link activities that are threatened by polyarthritis with the associated higher goals. Distinguish between lower order and higher order goals. Discuss the four goal management strategies and their pros and cons and accompanying emotions.

Formulate the first threatened activity for the personal trajectory. Explore the feasibility of goal management strategies for resolving threatened activity. from self and social environment. skills and competencies. Evaluate progress during program.

\# Note. Adapted from Michie et al., 2008 [61]; Abraham \& Michie, 2008 [62]; and Vriezekolk et al., 2013 [63]. Behavioral information: provide information about antecedents or consequences of the behavior, or consequences between them, or behavior change techniques; Cognitive restructuring: changing cognitions about causes and consequences of behavior; Comparison: provide comparative data (cf. standard, person's consequences between them, or behavior change techniques; Cognitive restructuring: changing cognitions about causes and consequences of behavior; Comparison: provide comparative data (cf. standard, person's
own past behavior, others' behavior); Coping planning: identify and plan ways of overcoming barriers; Decision making: generate alternative courses of action, and pros and cons of each, and weigh them against each other; Emotional social support: other participants and trainer listen, provide empathy and give generalized positive feedback; Feedback: of (self-) monitored behavior; Goal review: assess extent to which the each other; Emotional social support: other participants and trainer listen, provide empathy and give generalized positive feedback; Feedback: of (self-) monitored behavior, Goal review: assess extent to which the others; Planning: identify component parts of behavior and make a plan to execute each one or consider when and/or where a behavior will be performed, i.e. schedule behaviors; Prompt: stimulus that elicits others; Planning: identify component parts of behavior and make a plan to execute each one or consider when and/or where a behavior will be performed, i.e. schedule behaviors; Prompt: stimulus that elicits
behavior (incl. telephone calls or email reminders designed to prompt the behavior); Record antecedents and consequences of behavior: social and environmental situations and events, emotions, cognitions; behavior (incl. telephone calls or email reminders designed to prompt the behavior); Record antecedents and consequences of behavior: social and environmental situations and events, emotions, cognitions;
Relapse prevention: identify situations that increase the likelihood of returning to a risk behavior or failing to perform a new behavior and help to plan how to avoid or manage the situation, so that new behavioral Relapse prevention: identify situations that increase the likelihood of returning to a risk behavior or failing to perform a new behavior and help to plan how to avoid or manage the situation, so that new behavioral
routines are maintained; Social comparison: provide opportunities for social comparison e.g., group learning; Vicarious reinforcement: observe the consequences of other's behavior. No definition available: General routines are maintained; Social comparison: provide opportunities for social comparison e.g., group learning; Vicarious reinforcement: observe th
problem solving; Information; Instruction; Mental rehearsal; Practice behavior; Problem identification; Reframing; Set homework tasks. comparison (with narratives and other participants), emotional social support (by other participants), set homework tasks, prompt (email after meeting to do

Information (goals, pyramid and hierarchy of goals), reframing (hierarchy of lower/ higher order goals), instruction, problem identification (goal hierarchy and main and consequences of behavior (discussion of goal management strategies), modeling (by other participants), cognitive restructuring (discussion of goal management strategies), emotional social support, set homework tasks, problem identification (homework: define threatened activity)

Information (general), feedback (group discussion on threatened activity), social comparison (group discussion), vicarious reinforcement (group discussion), general problem solving, record antecedents and consequences of behavior (mental simulation), imagery (mental simulation), mental rehearsal (mental simulation),
decision making (mental simulation) reframing (of goal management strategies by mental simulation), set homework tasks, planning (homework: write action plan)

Feedback (group discussion on action plan), social comparison (group discussion), vicarious reinforcement (group discussion), planning (action plan), coping planning (action plan), information (emotions and resistance), modeling (by personal role model), vicarious reinforcements (role model), set homework tasks, meeting to execute action plan)

Goal review (evaluation execution action plan), feedback, social comparison (group discussion), general problem solving, record antecedents and consequences of (mental simulation), decision making (mental simulation) reframing (of goa management strategies by mental simulation), cognitive restructuring (of goa management strategies), planning (action plan), coping planning (action plan), set homework tasks, practice behavior (execution of action plan and goal management strategy), relapse prevention (personal warning signs)

Goal review (evaluation execution action plan), feedback, social comparison (group discussion), relapse prevention (personal warning signs), coping planning (personal warning signs), cognitive restructuring (of goal management strategies), planning (plan actions for future), coping planning (plan actions for future) 


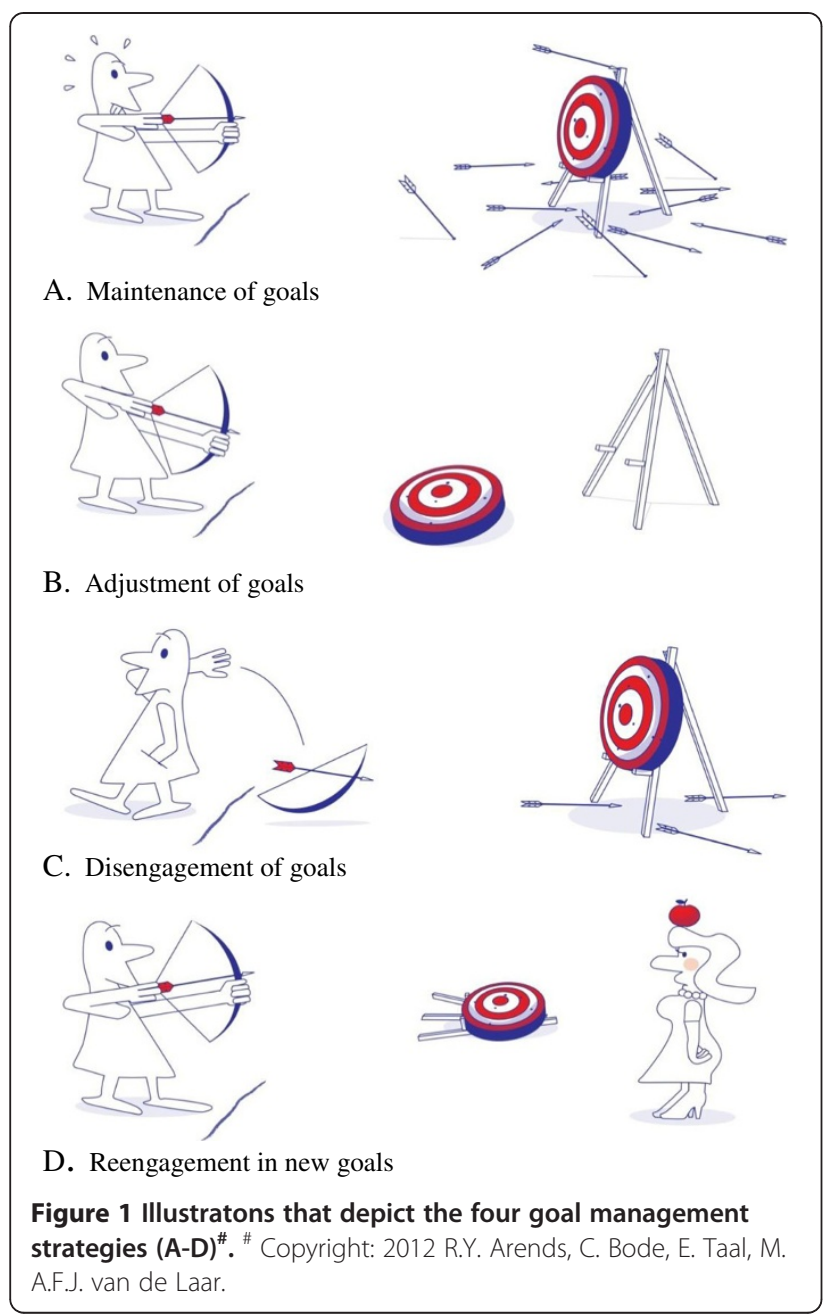

used to stimulate the flexible use of the goal management strategies. Those techniques are used regularly in psychosocial interventions: group discussions, personal feedback, planning, self-examination and mental simulation (see Table 2 for a complete list). In particular, the technique of mental simulation is used to stimulate people to apply a new, and until now not preferred, goal management strategy. Progress to achieve goals is reached through the mental simulation of the initiation and maintenance of activities that help to reach a goal [64]. This technique has shown its feasibility and effectiveness in other studies $[65,66]$.

\section{Trainers}

Specialized nurses in rheumatology care train and support the groups. Participants have the same trainer during the entire intervention period. Before the start of the program, the nurses received a full day 'train-the-trainer' course. In this training, the nurses worked through the entire program as a participant and completed the homework assignments to experience the techniques used in the program. In a second phase, the nurses gave the exercises

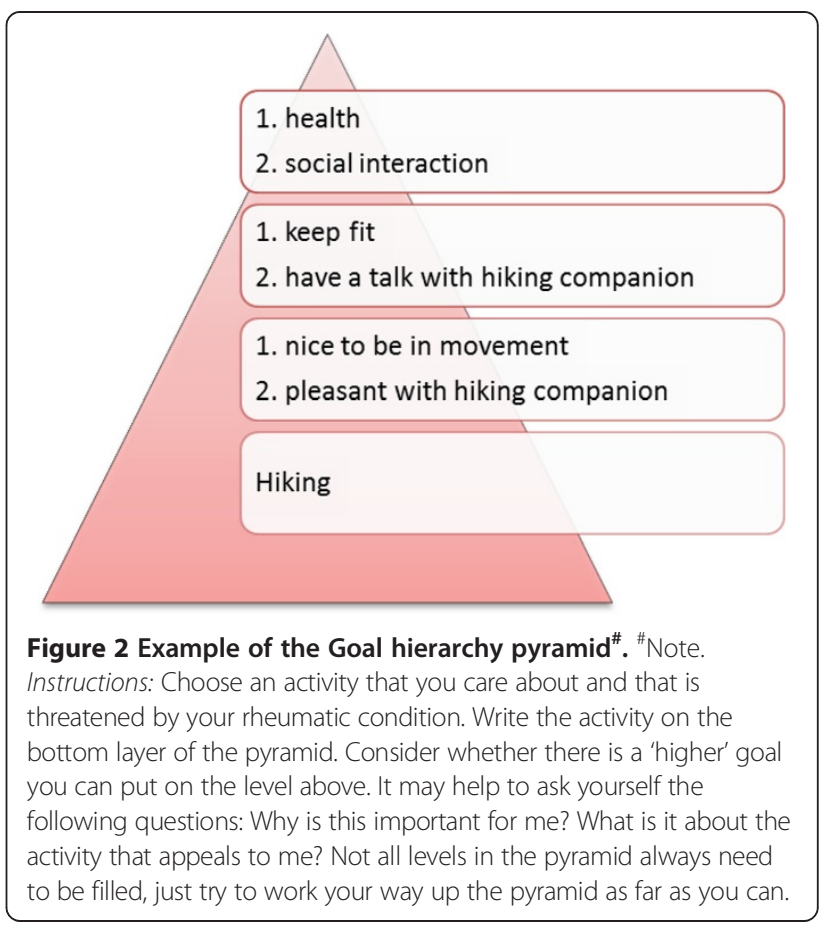

themselves and received detailed feedback on their performance. At the end of the train-the-trainer course, trainers' knowledge and skills concerning goal management and learned intervention techniques were evaluated. During the study period, trainers receive monitoring and regular supervision by a psychologist.

\section{Control condition}

Participants in the waiting list condition do not receive the "Right On Target" program immediately. Eight months after entry into the study, which is directly after the last follow-up measurement, participants on the waiting list are invited to follow the program.

\section{Measurements}

Table 3 gives an overview of the properties of the measurement instruments used. Participants are asked to complete six questionnaires including: intake, baseline (T0), directly after the end of the program (T1), 2 months after the end of the program (T2), 4 months after the end of the program (T3), and 6 months after the end of the program (T4). Nearly all the instruments listed in Table 3 were applied in a previous study with polyarthritis patients [12], and, when available, Cronbach's alphas from that previous study also appear in Table 3.

\section{Primary outcome measure}

\section{Depressive symptoms}

The depression subscale of the Hospital Anxiety and Depression Scale (HADS) [60] is used. The HADS was chosen because the scale is designed to measure the 
presence and severity of depressive and anxiety symptoms whilst limiting any confounding effects of physical illness symptoms by excluding somatic items. The HADS is used both in earlier studies with arthritis patients (e.g., [54] and in studies on goal management [57]), which facilitates comparison of study results. The HADS is also used in other interventions intended to influence depressive symptoms [76]. Concurrent validity of the HADS is very satisfactory and the measure has sufficient internal consistencies $[59,60]$.

\section{Secondary outcome measures}

Anxiety

The anxiety subscale of the HADS [60] is used to measure anxiety symptoms.

\section{Positive affect}

The positive subscale of the Positive and Negative Affect Schedule (PANAS) [67] is used for the measurement of positive affect.

\section{Purpose in life}

To assess the extent wherein participants experience a meaningful life, the Purpose In Life Scale (PIL) $[68,69]$ is used. This scale is comprised of 5 items about a person's experience with respect to the presence or absence of life goals. One question about everyday purpose in life is added to the PIL: 'Doing the things I do everyday is a source of deep pleasure and satisfaction'.

\section{Participation}

The Impact on Participation and Autonomy (IPA) [70] questionnaire assesses the participants' satisfaction with social participation. We use the subscales family role, autonomy outdoors, social relations, and work and education to quantify impediments in participation and autonomy.

\section{Pain}

The severity of pain in the past week is measured by a 1 -item visual analogue scale.

\section{Fatigue}

The severity of fatigue in the past week is measured by a 1 -item visual analogue scale.

\section{Physical functioning}

The physical functioning subscale of the RAND-36 $[71,72,77]$ is selected to measure physical functioning.

\section{Measures of mediation variables}

To measure the use of goal management strategies, we use three generic disease questionnaires, and one diseasespecific instrument especially designed to measure goal management in arthritis patients.

\section{Maintenance of goals and adjustment of goals}

The tendencies to use the strategies maintaining goals and adjusting goals are measured by the Tenacious Goal Pursuit and Flexible Goal Adjustment scales (FLEXTEN: TGP \& FGA subscales) [73].

\section{Goal disengagement and goal reengagement}

The tendencies to use the strategies goal disengagement and goal reengagement are measured with the Goal Adjustment Scale (GAS) [42].

\section{Goal management strategy vignettes}

We have developed vignettes for explorative purposes in this program called Goal Management Strategy Vignettes (GMSV). Three vignettes are used to measure the extent in which a person is flexible in thinking about goal management. The vignettes are short stories of a person with arthritis who struggles with threatened personal goals in the domains of social relationships, leisure time and autonomy. To respond, the participant writes down possible ways in which the vignette character can react to the situation described. To analyze the answers, deductive coding for similarity with pre-defined strategies is used. To measure flexibility in thinking of goal management, the increase in the number of strategies that are mentioned per time point is used.

\section{Coping versatility}

The versatility subscale of the Coping Flexibility Questionnaire (COFLEX) [51] is used to measure coping versatility.

\section{Self-efficacy}

To measure self-efficacy for coping with disease symptoms, the Arthritis Self-efficacy Scale (ASES) [30,78] pain and other symptoms subscales are used.

\section{Demographics and disease related measures Demographics}

Baseline measurement includes demographic variables, including sex, age, marital status, education and current state of employment.

\section{Disease characteristics}

Diagnosis, disease duration (in years since diagnosis) and number of co-morbidities are asked. The diagnosis is checked by a rheumatologist.

\section{Medication use and change of medication}

Use of medication is asked with an open-ended question: 'What medications do you currently use, as prescribed by your rheumatologist?' Furthermore, changes in medication are asked with the question: 'Has anything changed in your medication in the past two months? Response 
Table 3 Study parameters, properties of the corresponding instruments and their measurement point(s)

\begin{tabular}{|c|c|c|c|c|c|c|c|c|}
\hline Content & $\begin{array}{l}\text { Measurement } \\
\text { point }\end{array}$ & Scale & Reference & Example item & $\begin{array}{l}\text { Scale } \\
\text { range }\end{array}$ & $\begin{array}{l}\text { Cronbach's } \\
\text { alpha a }^{\text {a }}\end{array}$ & Items & Response options \\
\hline Depression & $\begin{array}{l}\text { Intake, T0, T1, } \\
\text { T4 }\end{array}$ & Hospital Anxiety and Depression Scale (HADS) & $\begin{array}{l}\text { Zigmond \& Snaith, } 1983 \\
\text { [60] }\end{array}$ & $\begin{array}{l}\text { I have lost interest in my } \\
\text { appearance. }\end{array}$ & $0-21$ & .81 & 7 & $\begin{array}{l}\text { various response } \\
\text { format }(0-3)\end{array}$ \\
\hline Anxiety & $\begin{array}{l}\text { Intake, T0, T1, } \\
\text { T4 }\end{array}$ & HADS & Zigmond \& Snaith, 1983 & I feel tense or wound up. & $0-21$ & .83 & 7 & $\begin{array}{l}\text { various response } \\
\text { format }(0-3)\end{array}$ \\
\hline Positive affect & $\mathrm{T} 0, \mathrm{~T} 1, \mathrm{~T} 4$ & $\begin{array}{l}\text { Positive subscale of the Positive and Negative } \\
\text { Affect Schedule (PANAS) }\end{array}$ & $\begin{array}{l}\text { Watson, Clark, \& Tellegen, } \\
1988 \text { [67] }\end{array}$ & $\begin{array}{l}\text { Rate how you felt during the } \\
\text { past week: e.g., attentive, } \\
\text { interested. }\end{array}$ & $10-50$ & .92 & 10 & $\begin{array}{l}\text { very slightly or not at } \\
\text { all (1) - very much (5) }\end{array}$ \\
\hline Purpose in life & $\mathrm{T} 0, \mathrm{~T} 1, \mathrm{~T} 4$ & Purpose In Life scale (PIL) & $\begin{array}{l}\text { Ryff, } 1989 \text { [68]; Ryff \& } \\
\text { Keyes, } 1995 \text { [69] }\end{array}$ & $\begin{array}{l}\text { My daily activities often seem } \\
\text { trivial and unimportant to me. }\end{array}$ & $6-30$ & .82 & 6 & $\begin{array}{l}\text { strongly disagree } \\
\text { (1) -strongly agree (5) }\end{array}$ \\
\hline $\begin{array}{l}\text { Social } \\
\text { participation }\end{array}$ & $\mathrm{T} 0, \mathrm{~T} 1, \mathrm{~T} 4$ & $\begin{array}{l}\text { Family role, autonomy outdoors, social } \\
\text { relations and work and education subscales of } \\
\text { the Impact on Participation and Autonomy } \\
\text { (IPA) questionnaire }\end{array}$ & $\begin{array}{l}\text { Cardol, De Haan, De Jong, } \\
\text { Van den Bos, \& De Groot, } \\
2001 \text { [70] }\end{array}$ & $\begin{array}{l}\text { Domain autonomy outdoors: } \\
\text { The possibility to spend my } \\
\text { (spare) time like I want to is... }\end{array}$ & $0-4$ & .76 & 25 & $\begin{array}{l}\text { very good (0) - very } \\
\text { poor (4) }\end{array}$ \\
\hline Pain & $\mathrm{T} 0, \mathrm{~T} 1, \mathrm{~T} 4$ & 1 item with $100 \mathrm{~mm}$ visual analogue scale & - & $\begin{array}{l}\text { Please indicate how much pain } \\
\text { you had in the last } 7 \text { days due } \\
\text { to your condition? }\end{array}$ & $0-100$ & - & 1 & $\begin{array}{l}\text { no pain at all }(0)- \\
\text { unbearable pain }(100)\end{array}$ \\
\hline Fatigue & $\mathrm{T} 0, \mathrm{~T} 1, \mathrm{~T} 4$ & 1 item with $100 \mathrm{~mm}$ visual analogue scale & - & $\begin{array}{l}\text { Please indicate your level of } \\
\text { fatigue averaged over the past } 7 \\
\text { days? }\end{array}$ & $0-100$ & - & 1 & $\begin{array}{l}\text { no fatigue (0) - } \\
\text { completely } \\
\text { exhausted (100) }\end{array}$ \\
\hline $\begin{array}{l}\text { Physical } \\
\text { functioning }\end{array}$ & $\mathrm{T} 0, \mathrm{~T} 1, \mathrm{~T} 4$ & RAND-36 physical function subscale & $\begin{array}{l}\text { Ware \& Sherbourne, } 1992 \\
\text { [71]; Van der Zee \& } \\
\text { Sanderman, } 2012 \text { [72] }\end{array}$ & $\begin{array}{l}\text { Does your health limit you in } \\
\text { these activities? If so, how } \\
\text { much? E.g., Walking a half mile. }\end{array}$ & $10-30$ & - & 10 & $\begin{array}{l}\text { Yes, limited a lot (1) } \\
- \text { No, not limited at } \\
\text { all (3) }\end{array}$ \\
\hline $\begin{array}{l}\text { Goal } \\
\text { maintenance }\end{array}$ & $\mathrm{T} 0, \mathrm{~T} 1, \mathrm{~T} 4$ & Tenacious Goal Pursuit (TGP) & $\begin{array}{l}\text { Brandtstädter \& Renner, } \\
1990 \text { [73] }\end{array}$ & $\begin{array}{l}\text { When faced with difficulties, I } \\
\text { usually double my efforts. }\end{array}$ & $15-75$ & .73 & 15 & $\begin{array}{l}\text { strongly disagree (1) } \\
\text {-strongly agree (5) }\end{array}$ \\
\hline $\begin{array}{l}\text { Goal } \\
\text { adjustment }\end{array}$ & $\mathrm{T} 0, \mathrm{~T} 1, \mathrm{~T} 4$ & Flexible Goal Adjustment Scale (FGA) & $\begin{array}{l}\text { Brandtstädter \& Renner, } \\
1990\end{array}$ & $\begin{array}{l}\text { I adapt quite easily to changes in } \\
\text { plans or circumstances. }\end{array}$ & 15-75 & .79 & 15 & $\begin{array}{l}\text { strongly disagree (1) } \\
\text {-strongly agree (5) }\end{array}$ \\
\hline $\begin{array}{l}\text { Goal } \\
\text { disengagement }\end{array}$ & $\mathrm{TO}, \mathrm{T} 1, \mathrm{~T} 4$ & Goal Adjustment Scale & $\begin{array}{l}\text { Wrosch, Scheier, Miller, } \\
\text { et al., } 2003 \text { [42] }\end{array}$ & $\begin{array}{l}\text { If I have to stop pursuing an } \\
\text { important goal in my life, it's } \\
\text { easy for me to reduce my effort } \\
\text { towards a goal. }\end{array}$ & $4-20$ & .53 & 4 & $\begin{array}{l}\text { Strongly disagree (1) } \\
\text {-strongly agree (5) }\end{array}$ \\
\hline $\begin{array}{l}\text { Goal } \\
\text { reengagement }\end{array}$ & $\mathrm{T} 0, \mathrm{~T} 1, \mathrm{~T} 4$ & Goal Adjustment Scale & $\begin{array}{l}\text { Wrosch, Scheier, Miller, } \\
\text { et al., } 2003\end{array}$ & $\begin{array}{l}\text { If I have to stop pursuing an } \\
\text { important goal in my life, I seek } \\
\text { other meaningful goals. }\end{array}$ & $6-30$ & .88 & 6 & $\begin{array}{l}\text { strongly disagree (1) } \\
\text {-strongly agree (5) }\end{array}$ \\
\hline $\begin{array}{l}\text { Goal } \\
\text { management } \\
\text { strategies }\end{array}$ & $\mathrm{T} 0, \mathrm{~T} 1, \mathrm{~T} 4$ & Goal Management Strategy Vignettes (GMSV) & & See article's text & - & - & - & Open ended \\
\hline $\begin{array}{l}\text { Coping } \\
\text { versatility }\end{array}$ & $\mathrm{T} 0, \mathrm{~T} 1, \mathrm{~T} 4$ & Coping Flexibility Questionnaire (COFLEX) & $\begin{array}{l}\text { Vriezekolk, Van Lankveld, } \\
\text { Eijsbouts, Van Helmond, } \\
\text { Geenen, \& Van den Ende, }\end{array}$ & $\begin{array}{l}\text { I can easily change my approach } \\
\text { if necessary. }\end{array}$ & $9-36$ & - & 9 & $\begin{array}{l}\text { rarely or never (1) - } \\
\text { almost always (4) }\end{array}$ \\
\hline
\end{tabular}


Table 3 Study parameters, properties of the corresponding instruments and their measurement point(s) (Continued)

\begin{tabular}{|c|c|c|c|c|c|c|c|c|}
\hline $\begin{array}{l}\text { Self-efficacy } \\
\text { pain }\end{array}$ & $\mathrm{T} 0, \mathrm{~T} 1, \mathrm{~T} 4$ & Arthritis Self-Efficacy Scale & Lorig, et al., 1989 [30] & $\begin{array}{l}\text { I am certain that I can keep } \\
\text { arthritis pain from interfering } \\
\text { with my sleep. }\end{array}$ & $1-5$ & .83 & 5 & $\begin{array}{l}\text { strongly disagree (1) } \\
\text {-strongly agree (5) }\end{array}$ \\
\hline $\begin{array}{l}\text { Self-efficacy for } \\
\text { other } \\
\text { symptoms }\end{array}$ & $\mathrm{T} 0, \mathrm{~T} 1, \mathrm{~T} 4$ & Arthritis Self-Efficacy Scale & Lorig, et al., 1989 & $\begin{array}{l}\text { I am certain that I can control } \\
\text { my fatigue. }\end{array}$ & $1-5$ & .82 & 6 & $\begin{array}{l}\text { strongly disagree (1) } \\
\text {-strongly agree (5) }\end{array}$ \\
\hline Demographics & T0 & $\begin{array}{l}\text { Sex, age, marital status, education and current } \\
\text { state of employment }\end{array}$ & - & - & - & N.A. & 6 & $\begin{array}{l}\text { various response } \\
\text { format }\end{array}$ \\
\hline $\begin{array}{l}\text { Disease } \\
\text { characteristics }\end{array}$ & T0 & Diagnosis and disease duration & - & - & - & N.A. & 2 & $\begin{array}{l}\text { Various response } \\
\text { format }\end{array}$ \\
\hline Co-morbidities & T0 & Checklist with 15 categories of conditions ${ }^{b}$ & $\begin{array}{l}\text { Based on the International } \\
\text { Classification of Diseases } \\
\text { (ICD-10: WHO, 1992) }\end{array}$ & - & $0-16$ & N.A. & 16 & - \\
\hline Medication use & $\begin{array}{l}\mathrm{T} 0, \mathrm{~T} 1, \mathrm{~T} 2, \mathrm{~T} 3 \\
\mathrm{~T} 4\end{array}$ & - & - & See article's text & N.A. & N.A. & 2 & See text \\
\hline Utilities & $\mathrm{T} 0, \mathrm{~T} 1, \mathrm{~T} 4$ & EQ-5D & $\begin{array}{l}\text { Brooks, } 1996 \text { [74]; Lamers, } \\
\text { McDonnell, Stalmeier, } \\
\text { Krabbe, \& Busschbach, } \\
2006 \text { [75] }\end{array}$ & $\begin{array}{l}\text { I have no problems in walking } \\
\text { about. }\end{array}$ & $1-3$ & - & 15 & $\begin{array}{l}\text { No problem (1) - } \\
\text { extreme problems } \\
\text { (3) }\end{array}$ \\
\hline $\begin{array}{l}\text { Direct medical } \\
\text { costs }\end{array}$ & $\begin{array}{l}\text { T0, T1, T2, T3, } \\
\text { T4 }\end{array}$ & - & - & See article's text & N.A. & N.A. & 3 & Open ended \\
\hline $\begin{array}{l}\text { Indirect non- } \\
\text { medical costs }\end{array}$ & $\begin{array}{l}\mathrm{T} 0, \mathrm{~T} 1, \mathrm{~T} 2, \mathrm{~T} 3 \\
\mathrm{~T} 4\end{array}$ & - & - & See article's text & N.A. & N.A. & 7 & Open ended \\
\hline Price estimate & $\mathrm{T} 1$ & - & - & See article's text & N.A. & N.A. & 1 & $\begin{array}{l}\text { In euros for de } \\
\text { complete course }\end{array}$ \\
\hline
\end{tabular}

${ }^{\mathrm{a}}$ Arends et al., 2013; ${ }^{\mathrm{b}}$ Respondents could also indicate 'other conditions not listed'. 
options are: 'No' and 'Yes, I started a new drug. / I stopped a drug. / The dose of a drug is increased. I The dose of a drug has been reduced'.

\section{Measures for the economic evaluation Utilities}

The EuroQol-5D (EQ-5D) [74,75] is used to assess utilities. The EQ-5D descriptive system consists of five dimensions: mobility, self-care, usual activities, pain/ discomfort and anxiety/depression [75]. Furthermore, the 'thermometer' is asked; patients rate their health status on a scale from 0 (worst possible health) to 100 (best possible health).

\section{Direct medical costs}

Medical costs are collected on a bimonthly basis. Patients are asked the number of telephone consultations they have with their GP, as well as their number of visits to the GP, medical specialist, other paramedical and alternative therapists, and hospital days.

\section{Indirect non-medical costs}

Indirect non-medical costs are collected at the same frequency as the direct medical costs. Patients are asked about their absenteeism from work, domestic care, domestic help, and informal care.

\section{Price estimate}

Participants in the program group are asked at the postintervention $\mathrm{T} 1$ measurement how many euros they would spend for participation in this program if no health insurance would pay the costs.

\section{Measures for the process evaluation}

A brief questionnaire about the general evaluation of the session, the content, material, exercises and the presentation of the trainer is completed by the participants after each session. The trainers also fill in a short evaluation form at the end of each session and a comprehensive evaluation sheet at the end of each program.

\section{Measures for the competence of group trainers}

During the first two courses, the trainers receive onehour supervision after every session, and afterwards supervision occurs less frequently, but on a regular basis. Random sessions are recorded with a voice recorder and checked for correct delivery of the protocol.

\section{Stakeholders' analysis measures}

At the end of a program, two participants per group are randomly chosen and interviewed to evaluate the program with the use of a structured interview scheme. At the end of the study, all the trainers and one person of the management team of the participating clinics are asked during a structured interview to evaluate the program and give suggestions for implementation.

\section{Sample size}

The sample size calculation is based on depressive symptoms as a primary objective. In order to demonstrate a medium-sized effect (Cohen's $d=0.40$ ), 100 participants in each condition are required, based on a statistical power (1-beta) of 0.80, a two-sided test and an alpha of 0.05 (power calculation with G-power).

\section{Analysis \\ Preliminary analysis}

A flow chart of participation during the total study will be drawn. Reasons for dropout will be summarized. Percentages of missing values and dropout will be displayed. Background variables and summarized scores on questionnaires will be given. One-way ANOVA'S and $X^{2}$-tests will be performed to check for differences between the two conditions at baseline for any of the demographic variables and/or outcome measures. Intention to treatanalyzes will be conducted with use of baseline (T0) or post-intervention (T1) data depending on the last present measurement data.

\section{Effectiveness analysis on primary and secondary outcome measures}

To examine differences between the two conditions on all outcome measures, analysis of variance for repeated measures (group x time) will be used. If demographic or outcome measures differ significantly between the groups at baseline, these measures will be incorporated into the analysis as covariate(s). Planned polynomial contrasts are used to analyze differences in effect of the program post-intervention and after the follow-up in the experimental group. Effect sizes of the experimental group in primary and secondary outcomes at postintervention and follow-up will be calculated with Cohen's D using the means and pooled standard deviations of the measurements of the conditions. Effect sizes are considered according to Cohen [79] as follows: small $\mathrm{d}=0.2$, medium $\mathrm{d}=0.5$, and large $\mathrm{d}=0.8$. To see if subgroups (e.g., high/low age, gender, disease severity) respond better to the program, subgroup analyzes will be calculated using independent t-tests or Mann-Whitney tests.

\section{Analysis of mediation}

Multiple mediation analysis will be performed to analyze whether the tendencies to use goal management strategies and coping versatility mediate the effects in the intervention. Primary and secondary outcomes used are the measures of depression, anxiety, purpose in life, positive affect and participation. Baseline and post- 
intervention measurements of both intervention and waiting list group will be used. A change score for tendencies to use goal management strategies and coping versatility will be computed with scores from baseline and post-intervention measurement. Multiple mediation analysis with bootstrapping procedures ( $\mathrm{n}=5000$ bootstrap re-samples) will be used to assess the indirect effect of the mediation pattern, as recommended by Preacher and Hayes [80]. An indirect effect will be considered significant in the case when zero is not contained in the 95\% bias-corrected confidence interval. Self-efficacy pain and self-efficacy for other symptoms will be incorporated in the multiple mediation analyzes as putative mediators. To analyze whether the GSMV mediate the effects of the intervention on the primary and secondary outcome measures, dummy variables will be used to indicate whether or not a strategy is named.

\section{Economic evaluation}

Results will be expressed as quality-adjusted life years (QALYs). The time-integrated summary score, which is the area under the curve (AUC) of the utilities, will be calculated to define the quality of life per time period (0-2 months and 0-8 months). Between-group differences in QALYs will be analyzed per period using t-test for unpaired observations. The costs will be presented as an arithmetic mean (+- SD) per patient per group. The between-group differences in resource use will be analyzed per period using the Mann-Whitney $U$ test. For every patient and study period, the mean incremental costs will be calculated, and, using double-sided bootstrapping, 95\% confidence intervals $(95 \% \mathrm{CI})$ will be estimated. The incremental cost utility ratio (ICER) will be calculated by dividing the extra costs for the goal management intervention by the extra QALYs derived from the goal management intervention. The ICER will be expressed as costs per QALY gained. The 95\% confidence intervals of the ratios will be estimated with bootstrapping. Cost evaluations will be conducted from the societal perspective and with a time-horizon of less than one year. Due to this short time-horizon, costs and effects will not be discounted.

\section{Discussion}

The purpose of the presented study protocol is to evaluate the effectiveness of the "Right On Target" program, a newly developed goal management intervention. We predict that the experimental condition will show positive effects compared with usual care in reducing depressive and anxiety symptoms and in improving positive affect, purpose in life and social participation, and will be cost effective. Both the program itself and its evaluation are likely to add to the existing body of knowledge in several ways, as described below.

\section{Strengths and limitations of the goal management intervention}

To the best of our knowledge "Right On Target" is the first program that focuses on the four goal management strategies of goal maintenance, goal adjustment, goal disengagement and goal reengagement to support improvement of adaptation to a chronic disease. The possibility to tailor the program to the personal needs of participants is expected to increase its effectiveness and participants' commitment to the program.

We provided a detailed description of the ingredients of the intervention, in accordance with the argument of Michie et al. [61], in order to communicate applied techniques that support the development of effective interventions and to improve knowledge regarding effective behavior change techniques. We hope to be able to identify the active ingredients in our intervention by clearly stating the underlying theory and assumed mechanisms of behavioral change.

Furthermore, the present study incorporates a holistic focus on adaptation, as the outcomes assessed are both the absence of psychological distress and the presence of well-being. Hence, this research focuses not only on the difficulties that people may experience due to a chronic disease, but also on personal sources of resilience.

As stated earlier in this paper, the goal management program focuses on dealing with threatened personal goals, rather than a pre-defined focus on disease-related goals. This program may ask for different competencies than health professionals are used to deploying in their daily practice. The specialized nurses in rheumatology care who provide the program have undergone extensive training. During the study period, the nurses receive regular guidance and supervision. Nevertheless, it is possible that nurses find it difficult to "sit on their hands" and not provide immediate solutions. This program might be less suitable without the extensive training and guidance of the nurses.

\section{Strengths and limitations of the randomized controlled trial}

Our study will hopefully answer questions regarding the effectiveness of the goal management intervention for patients with a rheumatic disease. We try to understand the pathways that are responsible for successful adaptation in persons dealing with a rheumatic disease and investigate who benefits most. In addition, we have included an economic evaluation. However, these additional analyzes cannot be conducted in absence of an effect of the goal management intervention compared to the waiting list group.

As the "Right On Target" program is a newly developed intervention, we execute a stakeholders' analysis. Experiences of participants, trainers and the management of the 
participating clinics provides insight into the feasibility regarding the intervention. The information from the stakeholders' analysis supports future implementation of the intervention.

\section{Conclusion}

To test the effectiveness of the "Right On Target" program to increase adaptation to polyarthritis, a randomized controlled trial is needed and a design for this study is presented. Results from this trial will test the effectiveness of the "Right On Target" program in improving the adaptation of patients to polyarthritis in terms of the absence of psychological distress and the presence of well-being. The protocol for the randomized controlled trial reflects a comprehensive view both on adaptation and on goal management. The presented study will add to the existing body of knowledge of health promotion interventions.

\section{Competing interests}

The authors declare that they have no competing interests.

\section{Authors' contributions}

RYA, CB, ET and MAFJL were responsible for conceiving and designing the study. All authors contributed to the development and critical evaluation of the study protocol. RYA drafted the manuscript and the other authors revised it critically and corrected draft versions. All authors read and approved the final manuscript.

\section{Acknowledgements}

We thank our two patient partners, Lynn Packwood and Klaas Sikkel, who added the patient perspective to this project. We thank Riëtte Leemreize-Mol for her valuable contribution to the intervention from her nursing perspective. The project is financially supported by the Stichting Reumaonderzoek Twente, a foundation for research in rheumatology.

\section{Author details}

${ }^{1}$ Arthritis Centre Twente, Enschede, The Netherlands. ${ }^{2}$ Department of Psychology, Health \& Technology, University of Twente,

P.O. Box 217, 7500 AE, Enschede, The Netherlands. ${ }^{3}$ Department for Rheumatology, Medisch Spectrum Twente, Enschede, The Netherlands.

Received: 26 June 2013 Accepted: 7 August 2013

Published: 13 August 2013

\section{References}

1. WHO: Constitution of the World Health Organization, Basic documents, Supplement, October 2006. Geneva: WHO; 2006.

2. Stuifbergen AK, Morris M, Jung JH, Pierini D, Morgan S: Benefits of wellness interventions for persons with chronic and disabling conditions: $\mathrm{A}$ review of the evidence. Disabil Health J 2010, 3(3):133-145.

3. Starfield B: The hidden inequity in health care. Int J Equity Health 2011, 10(1):1-3.

4. Wagner EH, Austin BT, Davis C, Hindmarsh M, Schaefer J, Bonomi A: Improving chronic illness care: translating evidence into action. Health Aff (Millwood) 2001, 20(6):64-78.

5. WHO: International classification of functioning, disability and health. Geneva, Switzerland: World Health Organization; 2001.

6. Geenen R, Newman S, Bossema ER, Vriezekolk JE, Boelen PA: Psychological interventions for patients with rheumatic diseases and anxiety or depression. Best Pract Res Clin Rheumatol 2012, 26(3):305-319.

7. Dickens C, McGowan L, Clark-Carter D, Creed F: Depression in Rheumatoid Arthritis: A Systematic Review of the Literature With Meta-Analysis. Psychosom Med 2002, 1(64):52-60.
8. VanDyke MM, Parker JC, Smarr KL, Hewett JE, Johnson GE, Slaughter JR, Walker SE: Anxiety in rheumatoid arthritis. Arthritis Care Res 2004, 51(3):408-412.

9. Frank RG, Beck NC, Parker JC, Kashani JH, Elliott TR, Haut AE, Smith E, Atwood C, Brownlee-Duffeck M, Kay DR: Depression in rheumatoid arthritis. J Rheumatol 1988, 15(6):920-925.

10. Murphy $S$, Creed F, Jayson M: Psychiatric disorder and illness behaviour in rheumatoid arthritis. Rheumatology (Oxford) 1988, 27(5):357-363.

11. Evers AWM, Kraaimaat FW, van Riel PLCM, de Jong AJL: Tailored cognitive-behavioral therapy in early rheumatoid arthritis for patients at risk: a randomized controlled trial. Pain 2002, 100(1-2):141-153.

12. Arends RY, Bode C, Taal E, Van de Laar MAFJ: The role of goal management for successful adaptation to arthritis. Patient Educ Couns 2013. Epub ahead of publication.

13. De Ridder D, Geenen R, Kuijer R, van Middendorp H: Psychological adjustment to chronic disease. Lancet 2008, 372(9634):246-255.

14. Lamers SM, Bolier L, Westerhof GJ, Smit F, Bohlmeijer ET: The impact of emotional well-being on long-term recovery and survival in physical illness: a meta-analysis. J Behav Med 2012, 35(5):538-547.

15. Strand EB, Kerns RD, Christie A, Haavik-Nilsen K, Klokkerud M, Finset A: Higher levels of pain readiness to change and more positive affect reduce pain reports - A weekly assessment study on arthritis patients. Pain 2007, 127(3):204-213.

16. Zautra AJ, Johnson LM, Davis MC: Positive affect as a source of resilience for women in chronic pain. J Consult Clin Psychol 2005, 73(2):212-220.

17. Verduin PJM, de Bock GH, Vliet Vlieland TPM, Peeters AJ, Verhoef J, Otten W: Purpose in life in patients with rheumatoid arthritis. Clin Rheumatol 2008, 27(7):899-908

18. De Croon EM, Sluiter JK, Nijssen TF, Dijkmans BAC, Lankhorst GJ, Frings-Dresen MHW: Predictive factors of work disability in rheumatoid arthritis: A systematic literature review. Ann Rheum Dis 2004, 63(11):1362-1367.

19. Reinhardt JD, Stucki G: Rheumatoid arthritis and participation - The social animal revisited. J Rheumatol 2007, 34(6):1214-1216.

20. Sokka T, Kautiainen H, Pincus T, Verstappen S, Aggarwal A, Alten R, Andersone D, Badsha H, Baecklund E, Belmonte M, et al: Work disability remains a major problem in rheumatoid arthritis in the 2000s: data from 32 countries in the QUEST-RA Study. Arthritis Res Ther 2010, 12(2):R42.

21. Newman S, Steed L, Mulligan K: Self-management interventions for chronic illness. Lancet 2004, 364(9444):1523-1537.

22. Yach D: HCGCHKJ: The global burden of chronic diseases: Overcoming impediments to prevention and control. JAMA: The Journal of the American Medical Association 2004, 291(21):2616-2622.

23. Nolte $\mathrm{S}$, Osborne $\mathrm{RH}$ : A systematic review of outcomes of chronic disease self-management interventions. Qual Life Res 2012. Epub ahead of publication.

24. Barlow J, Wright C, Sheasby J, Turner A, Hainsworth J: Self-management approaches for people with chronic conditions: a review. Patient Educ Couns 2002, 48(2):177-187.

25. Nolte S, Elsworth GR, Newman S, Osborne RH: Measurement issues in the evaluation of chronic disease self-management programs. Qual Life Res 2012. Epub ahead of publication.

26. Lorig K, Holman H: Self-management education: History, definition, outcomes, and mechanisms. nn. Behav Med 2003, 26(1):1-7.

27. Iversen MD, Hammond A, Betteridge N: Self-management of rheumatic diseases: State of the art and future perspectives. Ann Rheum Dis 2010, 69(6):955-963.

28. Riemsma RP, Taal E, Kirwan JR, Rasker JJ: Systematic review of rheumatoid arthritis patient education. Arthritis Care Res 2004, 51(6):1045-1059.

29. Niedermann K, Fransen J, Knols R, Uebelhart D: Gap between short- and long-term effects of patient education in rheumatoid arthritis patients: A systematic review. Arthritis \& Rheumatism-Arthritis Care \& Research 2004, 51(3):388-398

30. Lorig K, Chastain RL, Ung E, Shoor S, Holman HR: Development and Evaluation of a Scale to Measure Perceived Self-Efficacy in People with Arthritis. Arthritis Rheum 1989, 32(1):37-44

31. Lorig K, Lubeck D, Kraines RG, Seleznick M, Holman HR: Outcomes of self-help education for patients with arthritis. Arthritis Rheum 1985, 28(6):680-685.

32. Stuifbergen AK: Building health promotion interventions for persons with chronic disabling conditions. Fam Community Health 2006, 29(1):28S-34S.

33. Paterson BL: The Shifting Perspectives Model of Chronic Illness. J Nurs Scholarsh 2001, 33(1):21-26. 
34. Starfield B: Is patient-centered care the same as person-focused care? The Permanente Journal 2011, 15(2):63.

35. Wrosch C, Scheier MF, Carver CS, Schulz R: The Importance of Goal Disengagement in Adaptive Self-Regulation: When Giving Up is Beneficial. Self \& Identity 2003, 2(1):1.

36. Scheier MF, Wrosch C, Baum A, Cohen S, Martire LM, Matthews KA, Schulz R, Zdaniuk B: The Life Engagement Test: Assessing Purpose in Life. J Behav Med 2006, 29(3):291-298.

37. Pomerantz EM, Saxon JL, Oishi S: The psychological trade-offs of goal investment. J Pers Soc Psychol 2000, 79(4):617-630.

38. Carver CS, Scheier MF: Origins and functions of positive and negative affect: A control-process view. Psychol Rev 1990, 97(1):19.

39. Brandtstädter J: Goal pursuit and goal adjustment: Self-regulation and intentional self-development in changing developmental contexts. Adv Life Course Res 2009, 14(1-2):52-62.

40. Brandtstädter J, Rothermund K: The life-course dynamics of goal pursuit and goal adjustment: A two-process framework. Dev Rev 2002, 22(1):117-150.

41. Schmitz U, Saile H, Nilges P: Coping with chronic pain: Flexible goal adjustment as an interactive buffer against pain-related distress. Pain 1996, 67(1):41-51.

42. Wrosch C, Scheier MF, Miller GE, Schulz R, Carver CS: Adaptive Self-Regulation of Unattainable Goals: Goal Disengagement, Goal Reengagement, and Subjective Well-Being. Pers Soc Psychol Bull 2003, 29(12):1494-1508.

43. Katz PP, Morris A, Yelin EH: Prevalence and predictors of disability in valued life activities among individuals with rheumatoid arthritis. Ann Rheum Dis 2006, 65(6):763-769.

44. Klippel JH, Crofford LJ, Stone JH, White PH: The social and economic consequences of rheumatic disease. In Primer on the Rheumatic Diseases. 12th edition. Edited by Klippel JH. Atlanta: Arthritis Foundation; 2008.

45. Scott DL, Smith C, Kingsley G: What are the consequences of early rheumatoid arthritis for the individual? Best Pract Res Clin Rheumatol 2005, 19(1):117-136

46. Lempp H, Scott D, Kingsley G: The personal impact of rheumatoid arthritis on patients' identity: A qualitative study. Chronic Illness 2006, 2(2):109-120.

47. Mancuso CA, Paget SA, Charlson ME: Adaptations made by rheumatoid arthritis patients to continue working: A pilot study of workplace challenges and successful adaptations. Arthritis Care Res 2000, 13(2):89-99.

48. Katz PP, Yelin EH: Activity loss and the onset of depressive symptoms: Do some activities matter more than others? Arthritis Rheum 2001, 44(5):1194-1202

49. Vriezekolk JE, van Lankveld WG, Geenen R, van den Ende CH: Longitudinal association between coping and psychological distress in rheumatoid arthritis: a systematic review. Ann Rheum Dis 2011, 70(7):1243-1250.

50. Folkman S, Moskowitz JT: Coping: Pitfalls and promise. Annu Rev Psychol 2004, 55:745-774.

51. Vriezekolk JE, van Lankveld WGJM, Eijsbouts AMM, van Helmond T, Geenen $\mathrm{R}$, van den Ende CHM: The coping flexibility questionnaire: development and initial validation in patients with chronic rheumatic diseases. Rheumatol Int 2012, 32(8):2383-2391.

52. Vriezekolk JE, Eijsbouts AMM, van Lankveld WGJM, Beenackers H, Geenen R, van den Ende CHM: An acceptance-oriented cognitive-behavioral therapy in multimodal rehabilitation: A pre-post test evaluation in highly distressed patients with rheumatic diseases. Patient Educ Couns 2013, 91(3):357-363.

53. Morris A, Yelin EH, Panopalis P, Julian L, Katz PP: Long-term patterns of depression and associations with health and function in a panel study of rheumatoid arthritis. J Health Psychol 2011, 16(4):667-677.

54. Kekow J, Moots R, Khandker R, Melin J, Freundlich B, Singh A: Improvements in patient-reported outcomes, symptoms of depression and anxiety, and their association with clinical remission among patients with moderate-to-severe active early rheumatoid arthritis. Rheumatology (Oxford) 2011, 50(2):401-409.

55. Edwards RR, Calahan C, Mensing G, Smith M, Haythornthwaite JA: Pain, catastrophizing, and depression in the rheumatic diseases. Nat Rev Rheumatol 2011, 7(4):216-224.

56. Boerner K: Adaptation to disability among middle-aged and older adults: The role of assimilative and accommodative coping. J Gerontol B Psychol Sci Soc Sci 2004, 59(1):35.

57. Garnefski N, Grol M, Kraaij V, Hamming JF: Cognitive coping and goal adjustment in people with Peripheral Arterial Disease: Relationships with depressive symptoms. Patient Educ Couns 2009, 76(1):132-137.
58. Neter E, Litvak A, Miller A: Goal disengagement and goal re-engagement among multiple sclerosis patients: Relationship to well-being and illness representation. Psychol Heal 2009, 24(2):175-186.

59. Spinhoven P, Ormel J, Sloekers PPA, Kempen GIJM, Speckens AEM, VanHemert AM: A validation study of the Hospital Anxiety and Depression Scale (HADS) in different groups of Dutch subjects. Psychol Med 1997, 27(2):363-370.

60. Zigmond AS, Snaith RP: The Hospital Anxiety and Depression Scale. Acta Psychiatr Scand 1983, 67(6):361-370.

61. Michie S, Johnston M, Francis J, Hardeman W, Eccles M: From Theory to Intervention: Mapping Theoretically Derived Behavioural Determinants to Behaviour Change Techniques. Appl Psychol 2008, 57(4):660-680.

62. Abraham C, Michie S: A taxonomy of behavior change techniques used in interventions. Health Psychol 2008, 27(3):379.

63. Vriezekolk JE, Eijsbouts AM, van Lankveld WG, Beenackers H, Geenen R, van den Ende $\mathrm{CH}$ : An acceptance-oriented cognitive-behavioral therapy in multimodal rehabilitation: A pre-post test evaluation in highly distressed patients with rheumatic diseases. Patient Educ Couns 2013, 91(3):357-363

64. Taylor SE, Pham LB, Rivkin ID, Armor DA: Harnessing the imagination: Mental simulation, self-regulation, and coping. Am Psychol 1998, 53(4):429.

65. Bode C, de Ridder DT, Kuijer RG, Bensing JM: Effects of an intervention promoting proactive coping competencies in middle and late adulthood. Gerontologist 2007, 47(1):42-51.

66. Bode C, de Ridder DTD, Bensing JM: Preparing for aging: Development, feasibility and preliminary results of an educational program for midlife and older based on proactive coping theory. Patient Educ Couns 2006, 61(2):272-278.

67. Watson D, Clark LA, Tellegen A: Development and Validation of Brief Measures of Positive and Negative Affect - the Panas Scales. J Pers Soc Psychol 1988, 54(6):1063-1070.

68. Ryff CD: In the Eye of the Beholder - Views of Psychological Well-Being among Middle-Aged and Older Adults. Psychol Aging 1989, 4(2):195-210.

69. Ryff CD, Keyes CLM: The Structure of Psychological Well-Being Revisited. J Pers Soc Psychol 1995, 69(4):719-727.

70. Cardol M, De Haan RJ, De Jong BA, Van den Bos GAM, De Groot IJM: Psychometric properties of the impact on participation and autonomy questionnaire. Arch Phys Med Rehabil 2001, 82(2):210-216.

71. Ware JE, Sherbourne CD: The MOS 36-item short-form health survey (SF-36): I. Conceptual framework and item selection. Med Care 1992, 30(6):473-483

72. Van der Zee K, Sanderman R: Het meten van de algemene gezondheidstoestand met de RAND-36, een handleiding. Second revised edition. UMCG Rijksuniversiteit Groningen, Research Institute SHARE; 2012.

73. Brandtstädter J, Renner G: Tenacious Goal Pursuit and Flexible Goal Adjustment - Explication and Age-Related Analysis of Assimilative and Accommodative Strategies of Coping. Psychol Aging 1990, 5(1):58-67.

74. Brooks R: EuroQol: the current state of play. Health Policy 1996, 37(1):53-72.

75. Lamers LM, McDonnell J, Stalmeier PFM, Krabbe PFM, Busschbach JJV: The Dutch tariff: results and arguments for an effective design for national EQ-5D valuation studies. Health Econ 2006, 15(10):1121-1132.

76. Bisson JI, Sheperd JP, Joy D, Probert R, Newcombe RG: Early cognitive-behavioural therapy for post-traumatic stress symptoms after physical injury. Br J Psychiatry 2004, 184(1):63-69.

77. Van der Zee Kl, Sanderman R, Heyink JW, de Haes H: Psychometric qualities of the RAND 36-Item Health Survey 1.0: a multidimensional measure of general health status. Int J Behav Med 1996, 3(2):104-122.

78. Taal E, Riemsma RP, Brus HLM, Seydel ER, Rasker JJ, Wiegman O: Group education for patients with rheumatoid arthritis. Patient Educ Couns 1993 , 20(2-3):177-187.

79. Cohen J: A power primer. Psychol Bull 1992, 112(1):155

80. Preacher KJ, Hayes AF: Asymptotic and resampling strategies for assessing and comparing indirect effects in multiple mediator models. Behavior research methods 2008, 40(3):879-891.

doi:10.1186/1471-2474-14-239

Cite this article as: Arends et al:: A goal management intervention for polyarthritis patients: rationale and design of a randomized controlled trial. BMC Musculoskeletal Disorders 2013 14:239. 